\title{
Efficacy of Balneotherapy and Mud Therapy in Patients with Knee Osteoarthritis: A Systematic Literature Review
}

\section{Effizienz von Balneotherapie und Peloidtherapie bei Patienten mit Knie-Arthrose: systematische Literaturrecherche}

Authors

Hafiz Muhammad Asim Raza1, Grazina Krutulyte¹, Inesa Rimdeikiene ${ }^{1}$, Raimondas Savickas²

\section{Affiliations \\ 1 Rehabilitation, Lithuanian University of Health Sciences, Kaunas \\ 2 Rehabilitation, Lithuanian University of Health Sciences Hospital Kauno klinikos, Kaunas}

Key words

knee osteoarthritis, systematic evidence scan, balneotherapy, mud therapy, Western Ontario, McMaster Universities Osteoarthritis Index

Schlüsselwörter

Kniearthrose, systematische Datenabfrage, Balneotherapie, Peloidtherapie, Arthroseindex der Universitäten Western Ontario und MacMaster

online publiziert $\quad 22.10 .2020$

Bibliography

Akt Rheumatol 2021; 46: 187-197

DOI 10.1055/a-1157-8570

ISSN 0341-051X

(c) 2020. Thieme. All rights reserved.

Georg Thieme Verlag KG, Rüdigerstraße 14,

70469 Stuttgart, Germany

Correspondence

Prof. Raimondas Savickas

Rehabilitation

Lithuanian University of Health Sciences

Hospital Kauno klinikos

Eiveniu 2

50009 Kaunas

Lithuania

Tel.: + 37068619797, Fax: + 37037326324

raimondas.savickas@kaunoklinikos.It

\section{ABSTRACT}

Objectives To identify literature reporting on thermal mineral water and mud therapy effectiveness on pain, stiffness and knee function in patients with knee osteoarthritis.
Design Systematic evidence scan of MEDLINE and PubMed was performed to identify the randomized controlled trial studies published from 2004 to December 2018.

Study selection Papers reporting the effect of balneotherapy and mud therapy for treating knee $\mathrm{OA}$, a duration of $\geq 2$ weeks and in which Western Ontario and McMaster Universities Osteoarthritis Index (WOMAC) scores were used as an outcome measure.

Data extraction Not RCT, Studies not in English.

Results A quantitative meta-analysis of ten studies (831 patients) was performed. Five clinical studies (407 patients) measured effectiveness of balneotherapy and there was significant difference between the groups in WOMAC pain score, WOMAC stiffness score and WOMAC function score, with the differences in favour of balneotherapy. Six clinical studies (500 patients) measured effectiveness of mud therapy and there was significant difference between the groups in WOMAC pain score, WOMAC stiffness score and WOMAC function score, with the differences in favour of mud therapy.

Conclusion This meta-analysis indicates that balneotherapy and mud therapy were clinically effective in relieving pain, stiffness, and improving function, as assessed by WOMAC score.

\section{ZUSAMMENFASSUNG}

Ziel Systematische Literaturrecherche zur Effizienz von Balneotherapie und Peloidtherapie hinsichtlich Schmerzen, Steifheit und Kniefunktion bei Patienten mit Kniearthrose.

Design Systematische Datenabfrage in MEDLINE und PubMed zur Identifizierung randomisierter kontrollierter Studien, die zwischen 2004 und Dezember 2018 publiziert wurden.

Einschlusskriterien Artikel über die Auswirkungen von Balneotherapie und Peloidtherapie auf die Behandlung von Kniearthrose bei einer Behandlungsdauer von $>2$ Wochen unter Verwendung der WOMAC-Arthroseindizes der Universitäten Western Ontario und McMaster.

Ausschlusskriterien Keine kontrollierten klinischen Studien, Studien nicht in englischer Sprache vorliegend.

Ergebnis Es wurde eine Metaanalyse von zehn Studien (831 Patienten) durchgeführt. In fünf klinischen Studien (407 Patienten) wurde die Wirksamkeit der Balneotherapie beurteilt. Es fand sich ein signifikanter Unterschied zwischen den Gruppen hinsichtlich der WOMAC-Scores zu Schmerzen, Steifheit 
und Funktion zugunsten der Balneotherapie. In sechs klinischen Studien (500 Patienten) wurde die Wirksamkeit der Peloidtherapie beurteilt. Hier zeigte sich ein signifikanter Unterschied zwischen den Gruppen hinsichtlich der WOMAC-Scores zu Schmerzen, Steifheit und Funktion zugunsten der Peloidtherapie.
Schlussfolgerungen Diese Metaanalyse zeigt die klinische Wirksamkeit von Balneotherapie und Peloidtherapie bei der Reduktion von Schmerzen und Steifheit und der Verbesserung der Funktion, beurteilt anhand der WOMAC-Scores.
Osteoarthritis (OA) is the most common musculoskeletal disorder in the world, especially in elderly; and in the next 20 years its prevalence is likely to increase due to aging and the growing rates of obesity [1]. Knee osteoarthritis (KOA), the most common localization of OA, is the major cause of 'years lived with disability' worldwide. Approximately it affects $10 \%$ of men and $18 \%$ of women over 60 years old and leads to the chronic pain and functional impairment with difficulty to perform activities of daily livings (ADLs) and can cause a marked reduction in Quality of Life (QoL) of patients [2-4].

According to evidence-based therapeutic recommendations, management of KOA includes pharmacological and non-pharmacological modalities. Non-pharmacological treatment mainly include lifestyle modifications, spa therapy, physical therapy and pharmacological therapy include the use of NSAIDs or selective COX-2 inhibitors and analgesics (such as acetaminophen, narcotics) to control pain and to improve the joint function; however, several adverse effects can occur especially in elderly patients [5, 8].

In many European and Middle Eastern countries, Spa therapy is one of the most commonly used non-pharmacological approaches for $\mathrm{OA}$ and comprises a broad spectrum of therapeutic modalities including balneotherapy, hydrotherapy, mud therapy and physiotherapy [6, 9]. In thermal spas several balneological treatment methods are used; however, balneotherapy and peloid/ mud therapy are in the milestones of most treatments. Thermo-mineral waters are effective due to its thermal, mechanical, and chemical properties and long-term effects can be achieved with such therapies. Also, peloids/mud therapy are organic or inorganic materials which are formed as a result of geological and/or biological processes and mineral or salt water from sea or lakes, and can be used in the forms of mud bath or mud packs for preventive, therapeutic, or rehabilitative goals [7].

The current meta-analysis of recent RCTs was therefore performed to determine the effectiveness of balneotherapy and mud therapy on relieving pain, stiffness, and improving function in patients with knee osteoarthritis. The integration of independent RCTs in this meta-analysis will reveal non-biased outcomes regarding effectiveness of balneotherapy and mud therapy in the treatment of knee OA.

\section{Research Methodology and Methods}

\section{Systematic literature search}

This meta-analysis was performed according to the PRISMA guidelines [11]. Search has been done through electronic database MEDLINE via PubMed for the articles on balneotherapy and/or mud therapy in the treatment of knee osteoarthritis in order to investigate the evidence of efficacy of the treatment. The articles published from 2004 to December 2018 were searched by using the key words "balneotherapy”, “mud therapy”, and "knee osteoarthritis”. Publications obtained from Medical Subject Heading (MeSH) by using Boolean operates using AND and OR were screened, The study flow diagram according to PRISMA statement is reported in the $>$ Fig. 1 .

\section{Inclusion and exclusion criteria}

Studies were included that examined the effect of balneotherapy or mud therapy alone or combined effect of balneotherapy with mud therapy for treating knee OA for duration of $\geq 2$ weeks. Studies were considered eligible if they met the following criteria: (I) clinical trials with patients who had diagnosis of knee OA confirming by criteria of American College of Rheumatology (ACR); (II) randomized clinical trials (RCT); (III) clinical trials who used Western Ontario and McMaster Universities Osteoarthritis Index (WOMAC) scores as the outcome measure; (IV) clinical trials whose main objectives were to analyse the effectiveness of balnoetherapy or mud therapy. The studies that were excluded from the meta-analysis were those: (I) that analysed the effect of balneotherapy or mud therapy in the joints other than knee; (II) studies were review articles; (III) studies that were not in English; (IV) study method was not described: $(V)$ studies whose sample size was $\leq 30$ individuals.

\section{Data extraction}

All the data were extracted from the full text and assessed independently. Each report was reviewed independently to identify the criteria of study enrolment, sample size of the included studies, type and characteristics of the treatment for the experimental and control group, intervention period, characteristics of water and mud, outcome measures, assessment points and follow up period and also the quality of publication were assessed. Author did not contact any of the authors of the trial.

\section{Measures of effects}

The outcome measures evaluated to determine the effectiveness of treatment with balneotherapy and mud therapy on patients with knee osteoarthritis included relief of pain, relief of stiffness and improvement of the functions of the diseased knees. The specific scores used as an outcome in this meta-analysis for pain and relief of stiffness were WOMAC pain and stiffness score. Functional improvement was assessed by using the WOMAC function score. In most publications, functional improvement were assessed by both WOMAC function score and Lequesne index; however, in this meta-analysis WOMAC function score was chosen because studies suggest that WOMAC function score is more sensitive than Lequesne index in monitoring the improvement of the symptoms [12]. 


\section{Quality assessment of the publications}

Cochrane risk of bias tool was used to access the risk of bias according to the following parameters: randomization, allocation concealment, blinding of participants and personnel, blinding of outcome assessment, incomplete outcome data, selective reporting, intention-to-treat (ITT) analysis and other bias [13]. The range of possible score is 0 to 2 ; higher the score represent the more bias ( $\triangleright$ Tab. 1). If intention-to-treat (ITT) was included in the study, the results were used in this meta-analysis.

\section{Statistical analyses}

All statistical analyses were performed by using the software Review Manager, version 5.3. Treatment effect size is calculated by dividing the difference in changes from baseline between groups by the pooled SD of outcomes among participants and reflected as standardized mean difference. According to the data provided in the studies, the results of last follow-up visit were chosen in this meta-analysis and the results of comparative effects are presented by the standardized mean difference (SMD) estimates with the $95 \%$ confidence intervals. Heterogeneity across studies was tested with Cochran's $Q$ test with significance set at $P<0.05$ and meas- ure of inconsistency $\mathrm{l}^{2}$ statistics as a second measure of heterogeneity that represent the percentage of total variation across studies. $I^{2}$ is a value between 0 and 100 , with $0 \%$ indicating no evidence of heterogeneity and 25,50 , and $75 \%$ referring to low, moderate, and high heterogeneity, respectively. A P-value $<0.05$ was considered statistically significant. Fixed-effects model was used to perform the meta-analysis if heterogeneity was not detected among included studies; otherwise, a random-effects model would be used $\left(p<0.05\right.$ or $\left.\mathrm{l}^{2}=50 \%\right)[14,15]$.

\section{RESULTS}

\section{Literature screening and literature characteristics}

Literature search initially identified 2805 citations, of which after full text assessment ten [10] studies were considered eligible for this meta-analysis [10,16-24]. A study flow diagram indicating the result of literature search and studies selection procedure for this meta-analysis is presented in $>$ Fig. 1. Main characteristics of all the included studies are summarized in $>$ Tab. 2 and 3. Efficacy of
Records identified in MEDLINE

MeSH Terms: "balneology", "osteoarthritis knee", "mud therapy", "therapeutics"

$(n=2805)$

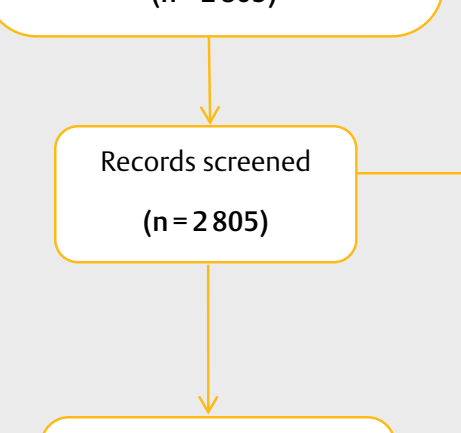

Full-text articles assessed for eligibility

$(n=40)$

Studies included in quantitative synthesis (meta-analysis)

$(n=10)$

\section{Records excluded}

$(n=2765)$

Reviews of OA $(n=234)$

Studies not in English $(n=653)$

Not human studies $(n=391)$

Not RCT $(n=1254)$

Articles studying other pathologies and other joints $(n=214)$

Not full text available $(n=19)$

Full-text articles excluded

$$
(n=30)
$$

Articles which applied BT and mud therapy but not isolated $(n=4)$

Did not use WOMAC score as an outcome $(n=7)$

Not complete clinical data $(\mathrm{n}=8)$

Not on clinical effect of

balneotherapy or mud therapy $(n=5)$

Sample size $\leq 30(n=6)$

- Fig. 1 Study flow diagram of the selection process for included studies. 
- Tab. 1 Quality assessment of all included studies in this meta-analysis.

\begin{tabular}{|c|c|c|c|c|c|c|c|c|c|}
\hline Study & Design & $\begin{array}{l}\text { Rand- } \\
\text { omiza- } \\
\text { tion }\end{array}$ & $\begin{array}{l}\text { Con- } \\
\text { ceal- } \\
\text { ment }\end{array}$ & $\begin{array}{l}\text { Blinding } \\
\text { (participants } \\
\text { and personnel) }\end{array}$ & $\begin{array}{l}\text { Blinding } \\
\text { (assess- } \\
\text { ment) }\end{array}$ & $\begin{array}{l}\text { ITT } \\
\text { analysis }\end{array}$ & $\begin{array}{l}\text { Incom- } \\
\text { plete } \\
\text { outcome }\end{array}$ & $\begin{array}{l}\text { Selective } \\
\text { outcome }\end{array}$ & $\begin{array}{l}\text { Other } \\
\text { bias }\end{array}$ \\
\hline $\begin{array}{l}\text { M. Tishler } \\
\text { et al. } 2004\end{array}$ & RCT & 0 & 0 & 1 & 2 & 2 & 0 & 0 & 1 \\
\hline $\begin{array}{l}\text { A. Fioravanti } \\
\text { et al. } 2010\end{array}$ & RCT & 0 & 1 & 1 & 0 & 0 & 0 & 0 & 0 \\
\hline $\begin{array}{l}\text { A. Faaza } \\
\text { et al. } 2014\end{array}$ & RCT & 0 & 0 & 1 & 0 & 2 & 0 & 0 & 1 \\
\hline $\begin{array}{l}\text { B. Uysal } \\
\text { et al. } 2018\end{array}$ & RCT & 0 & 1 & 1 & 0 & 2 & 0 & 0 & 1 \\
\hline $\begin{array}{l}\text { A. Hanzel } \\
\text { et al. } 2018\end{array}$ & RCT & 0 & 1 & 0 & 2 & 0 & 0 & 0 & 0 \\
\hline $\begin{array}{l}\text { L. Espejo } \\
\text { et al. } 2012\end{array}$ & RCT & 0 & 1 & 1 & 2 & 0 & 0 & 0 & 1 \\
\hline $\begin{array}{l}\text { G. Gungen } \\
\text { et al. } 2012\end{array}$ & RCT & 0 & 1 & 0 & 1 & 2 & 0 & 0 & 0 \\
\hline $\begin{array}{l}\text { I. Tefner } \\
\text { et al. } 2013\end{array}$ & RCT & 0 & 0 & 0 & 1 & 0 & 0 & 0 & 0 \\
\hline $\begin{array}{l}\text { A. Fioravanti } \\
\text { et al. } 2015\end{array}$ & RCT & 0 & 0 & 1 & 0 & 0 & 0 & 1 & 0 \\
\hline $\begin{array}{l}\text { NA. } \\
\text { Pascarelli } \\
\text { et al. } 2016\end{array}$ & RCT & 0 & 0 & 1 & 0 & 0 & 0 & 1 & 0 \\
\hline
\end{tabular}

balneotherapy and mud therapy was compared with the efficacy of standard treatment.

Standard treatment was combination of pharmacological and physical intervention which is characterized as drug based approach with the use of nonsteroidal anti-inflammatory drugs or other analgesics. Forty publications passed the initial screening and were further reviewed for their full text. Among those eight studies were excluded because of insufficient data, lack of control groups and results were presented as median (min-max) [25-32]. Seven studies did not use WOMAC scores to measure outcome, so they were also excluded [33-39].

The clinical studies included in this meta-analysis consisted of 435 balneotherapy and mud therapy cases and 396 control cases in total $[10,16-24]$. Among the included studies the smallest sample size was $n=30$ and the largest sample was $n=121$. The shortest duration of intervention was 11 days and the longest duration was 6 weeks. The shortest time to the last follow up was 11 days and the longest time to follow up was 12 months ( $>$ Tab. 2 and $\mathbf{3}$. There are 5 studies $[10,21-24]$ in which treatment approach in the therapeutic group were mud therapy and in four studies [17-20] the treatment approach were balneotherapy. In one study the treatment approach in the therapeutic group was mudpack therapy in combination with the balneotherapy [16]. One study [24] was the part of study [22]; however, it is also included in this meta-analysis because the last follow-up period in both studies was different.

\section{Meta-analysis of the effects of balneotherapy on WOMAC in patients with knee OA}

Among ten studies included in this meta-analysis, there were 5 clinical studies [16-20], including 218 treatment cases and 189 control cases that measured effectiveness of balneotherapy in patients with knee OA and measured WOMAC pain score as an outcome ( Fig. 2).

The result of this meta-analysis indicate that balneotherapy reduced the pain score by $-95 \%$ when compared with the controls, there was a significant difference between 2 groups ( $S M D=-0.95$; $95 \% \mathrm{Cl}-1.16$ to $-0.74 ; \mathrm{p}<0.000001)$. Statistical heterogeneity was not observed $\left(I^{2}=0 \% ; p=0.73\right)$.

These same 5 studies (16-20) also measured the WOMAC stiffness score as an outcome ( $\vee$ Fig. 3 ). The result of this meta-analysis indicate that balneotherapy improve the rate of relieving stiffness by $-44 \%$ when compared with the controls, there was significant difference between 2 groups ( $S M D=-0.44 ; 95 \% \mathrm{Cl}-0.80$ to $-0.09 ; p=0.02$ ). There was moderate degree of late statistical heterogeneity was observed across the studies $\left(I^{2}=62 \% ; p=0.03\right)$, which supported the application of random effects model (15). These same 5 studies [16-20] also measured the WOMAC function 


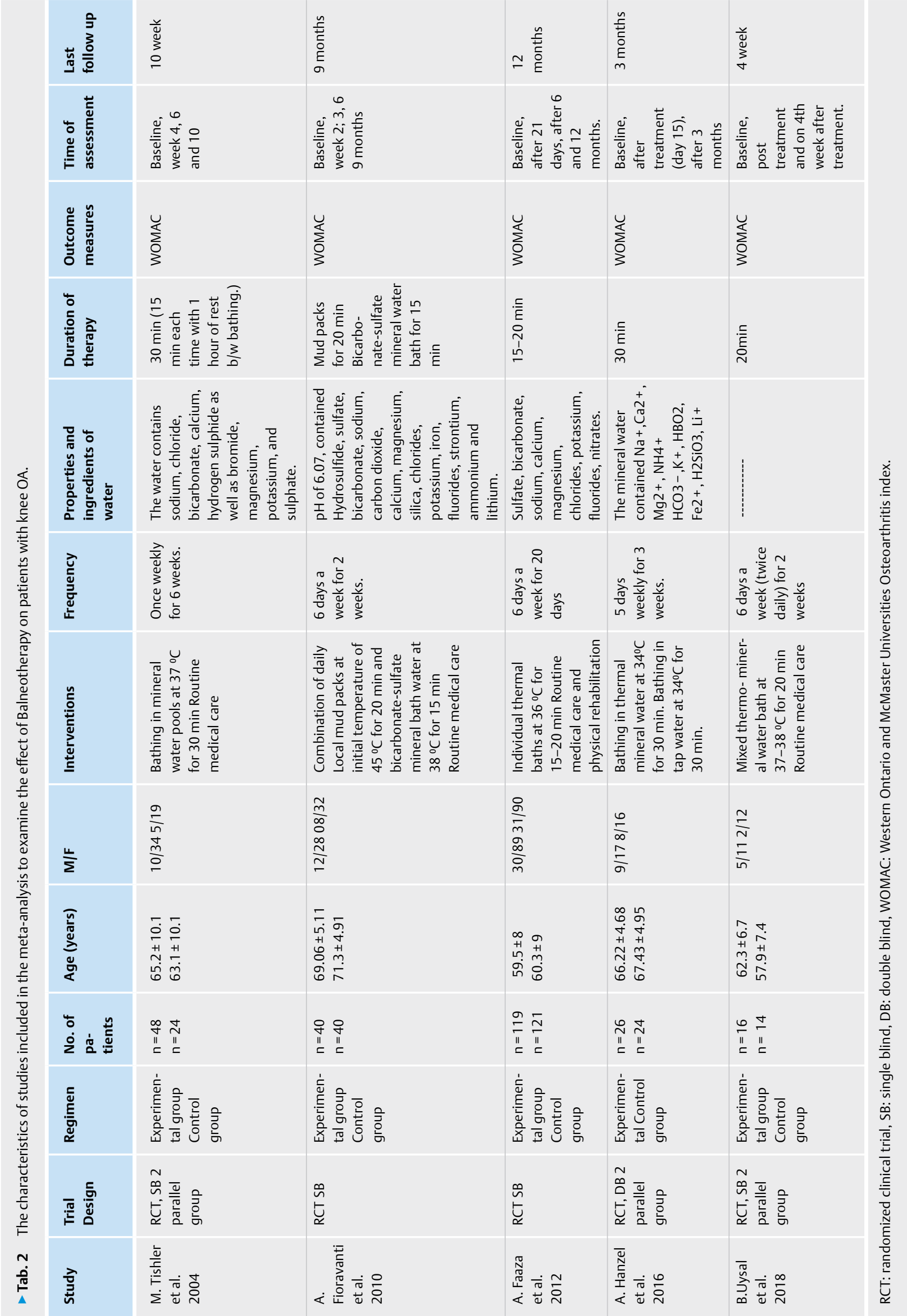




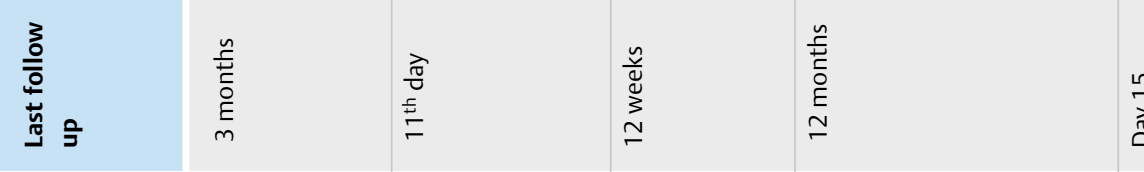

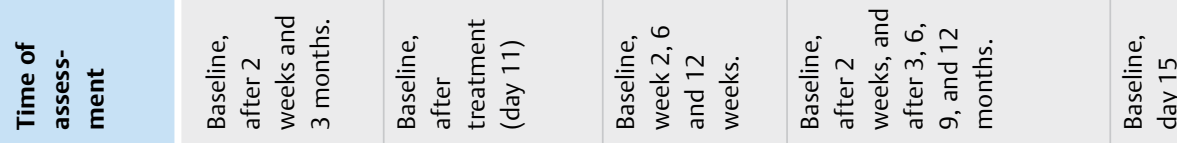

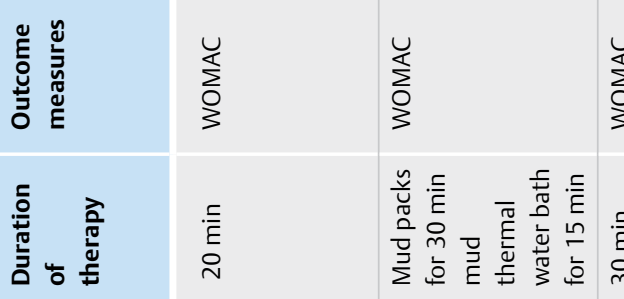

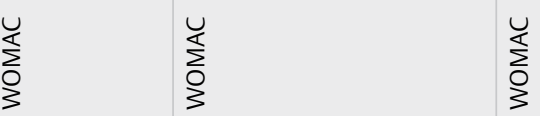

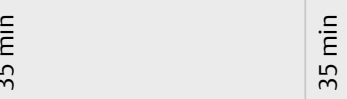

\begin{tabular}{|c|c|c|c|c|c|}
\hline 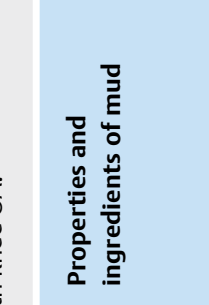 & 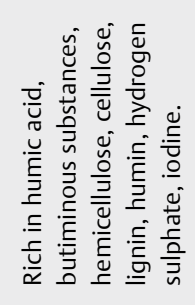 & 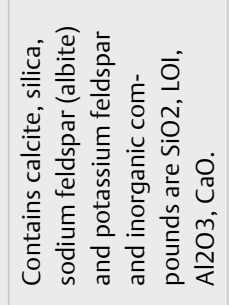 & 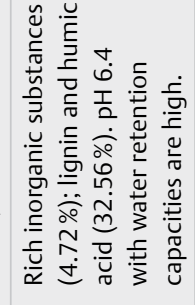 & 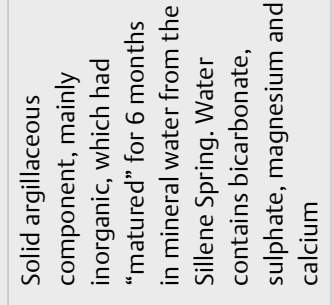 & 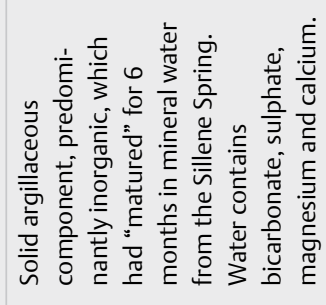 \\
\hline 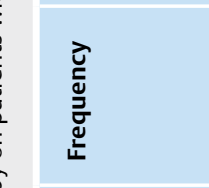 & 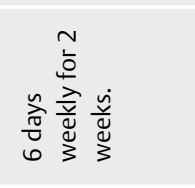 & 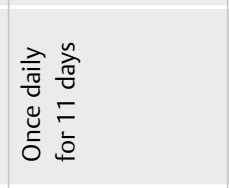 & 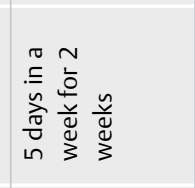 & 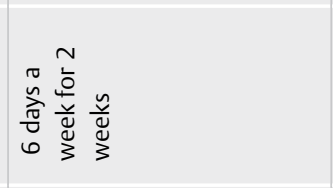 & 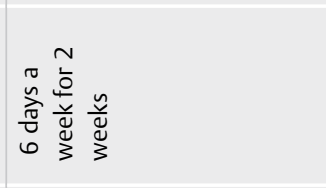 \\
\hline 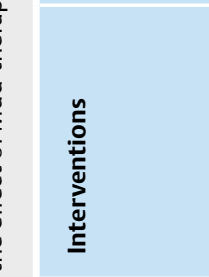 & 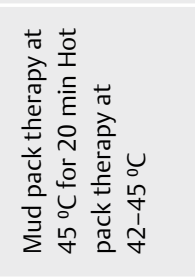 & 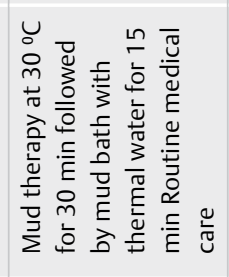 & 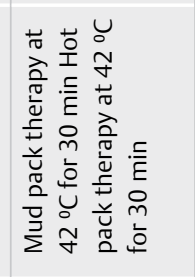 & 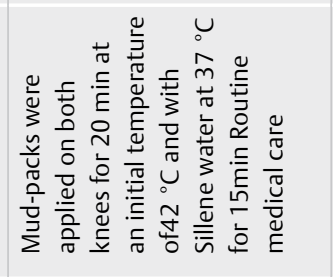 & 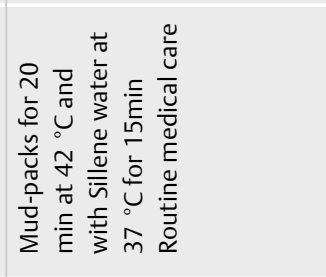 \\
\hline$\frac{\omega}{\Sigma}$ & $\frac{m}{0} \frac{N}{\sigma}$ & $\frac{\sqrt{2}}{\frac{d}{d}}$ & $\underset{\mathcal{F}}{\tilde{\mathcal{T}}} \frac{\tilde{N}}{}$ & 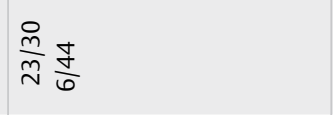 & $\frac{\stackrel{\rho}{m}}{\stackrel{n}{N}} \frac{f}{6}$ \\
\hline 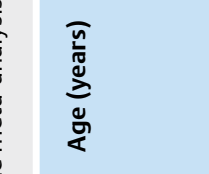 & 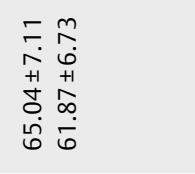 & 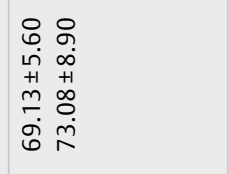 & 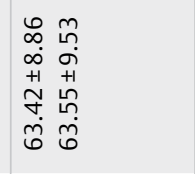 & 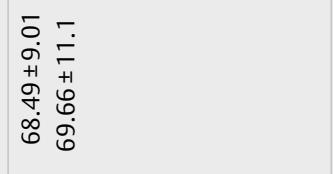 & $\begin{array}{ll}\bar{\sigma} & - \\
0 & = \\
+1 & = \\
+1 & +1 \\
0 & 0 \\
0 & 0 \\
0 & 0\end{array}$ \\
\hline 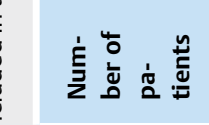 & $\stackrel{\stackrel{n}{N} \stackrel{n}{N}}{\| I}=\stackrel{\|}{=}$ & $\begin{array}{ll}5 & 8 \\
11 & 11 \\
= & =\end{array}$ & 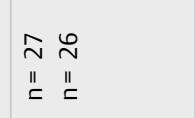 & $\begin{array}{ll}n & 0 \\
n & \text { in } \\
11 & \text { II } \\
= & \end{array}$ & $\begin{array}{ll}n & 0 \\
n & \text { in } \\
\text { II } & \text { II } \\
ᄃ\end{array}$ \\
\hline 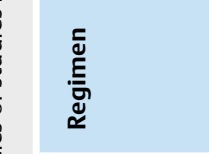 & 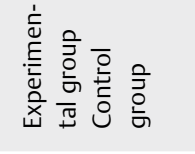 & 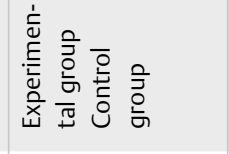 & 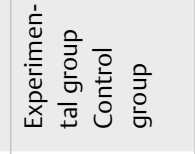 & 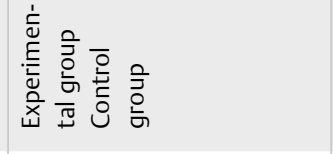 & 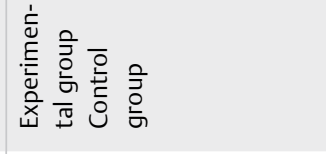 \\
\hline 愛 & 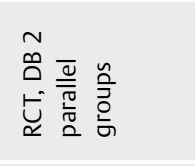 & 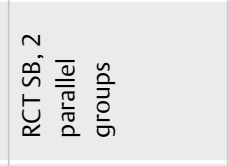 & 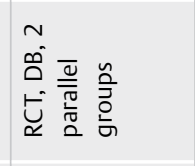 & 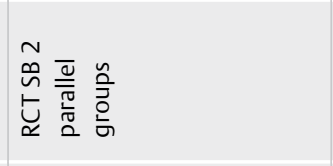 & 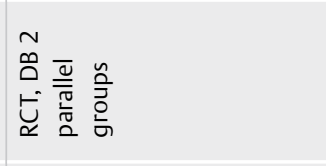 \\
\hline 离 & 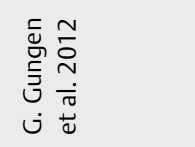 & 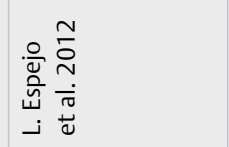 & 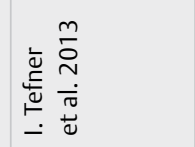 & 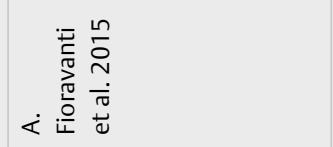 & 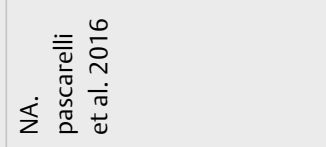 \\
\hline
\end{tabular}




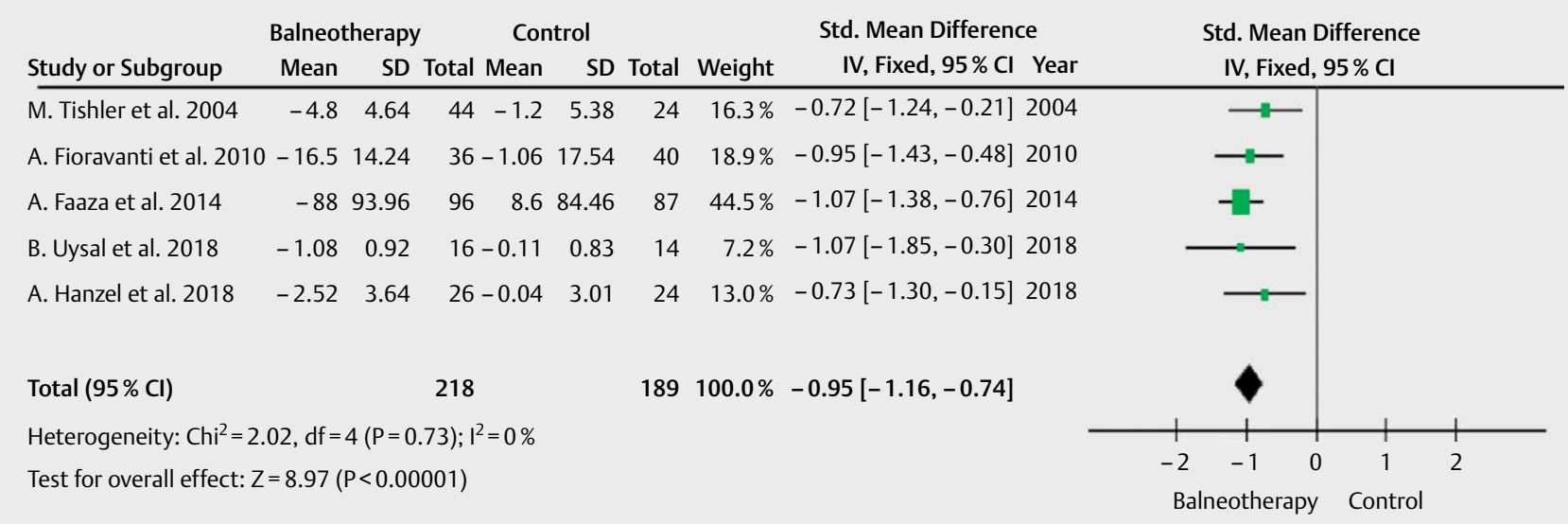

- Fig. 2 Forest plot of the mean differences in WOMAC pain scores with $95 \%$ confidence interval between balneotherapy group and control group to examine the effect of balneotherapy on pain relief in patients with knee OA.

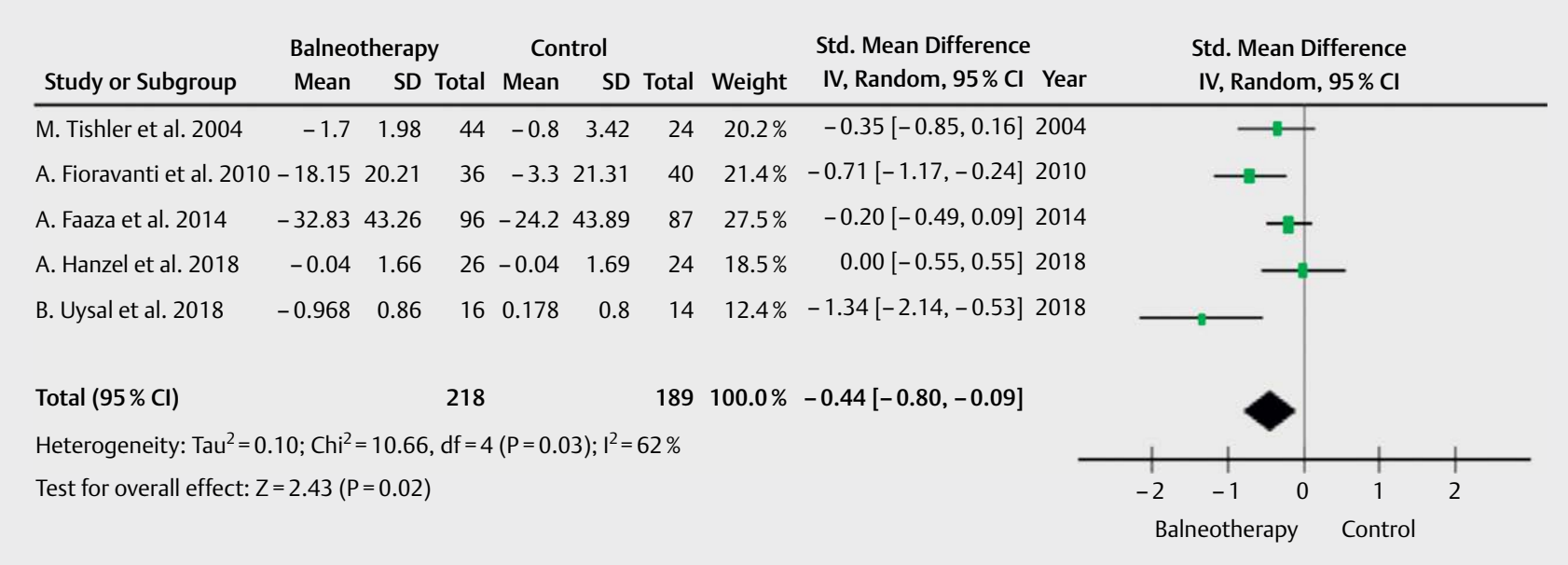

- Fig. 3 Forest plot of the mean differences in WOMAC stiffness scores with 95\% confidence interval between balneotherapy group and control group to examine the effect of balneotherapy on stiffness relief in patients with knee OA.

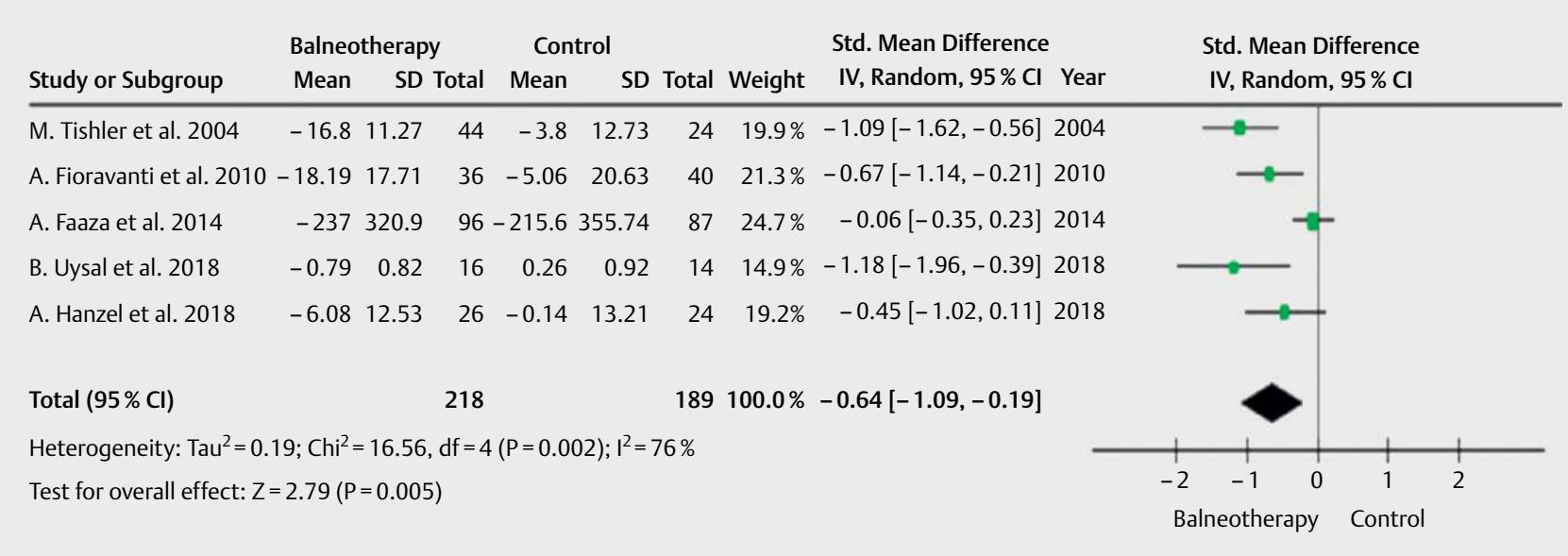

- Fig. 4 Forest plot of the mean differences in WOMAC function score with $95 \%$ confidence interval between balneotherapy group and control group to examine the effect of balneotherapy on improvement of physical function in patients with knee OA. 


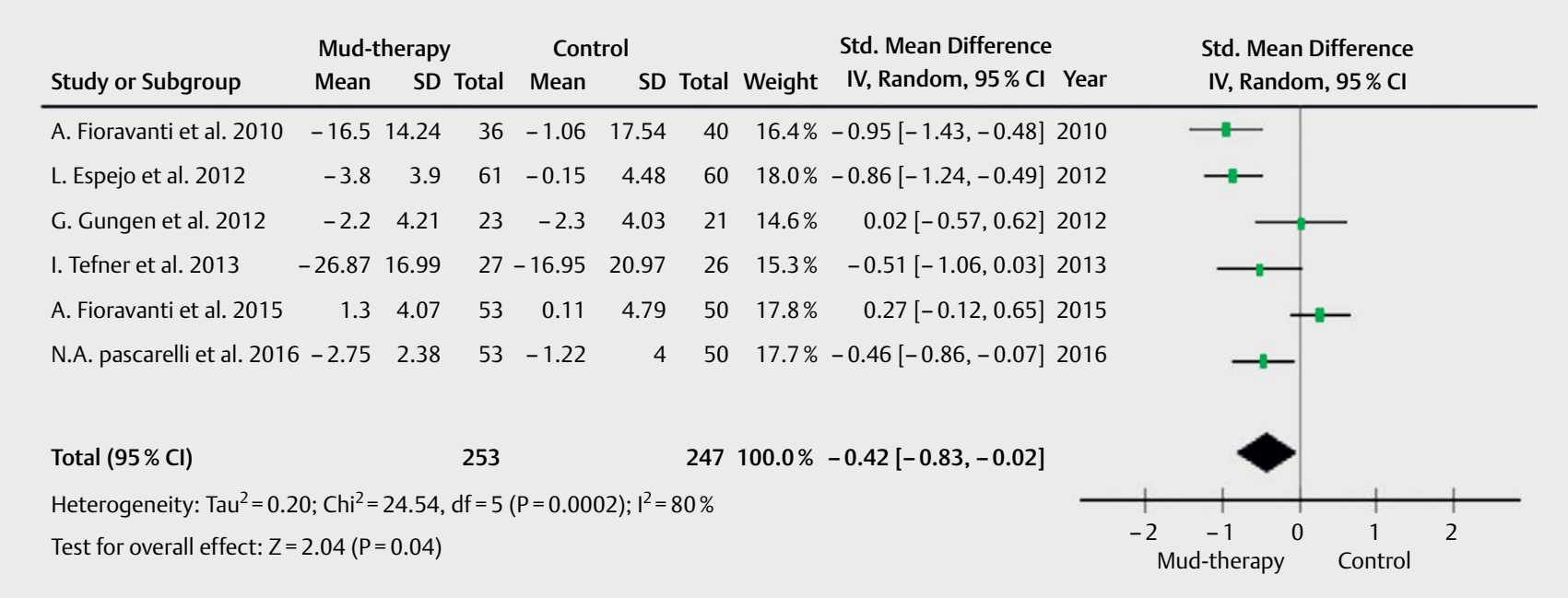

- Fig. 5 Forest plot of the mean differences in WOMAC pain scores with $95 \%$ confidence interval between mud therapy group and control group to examine the effect of mud therapy on pain relief in patients with knee OA.

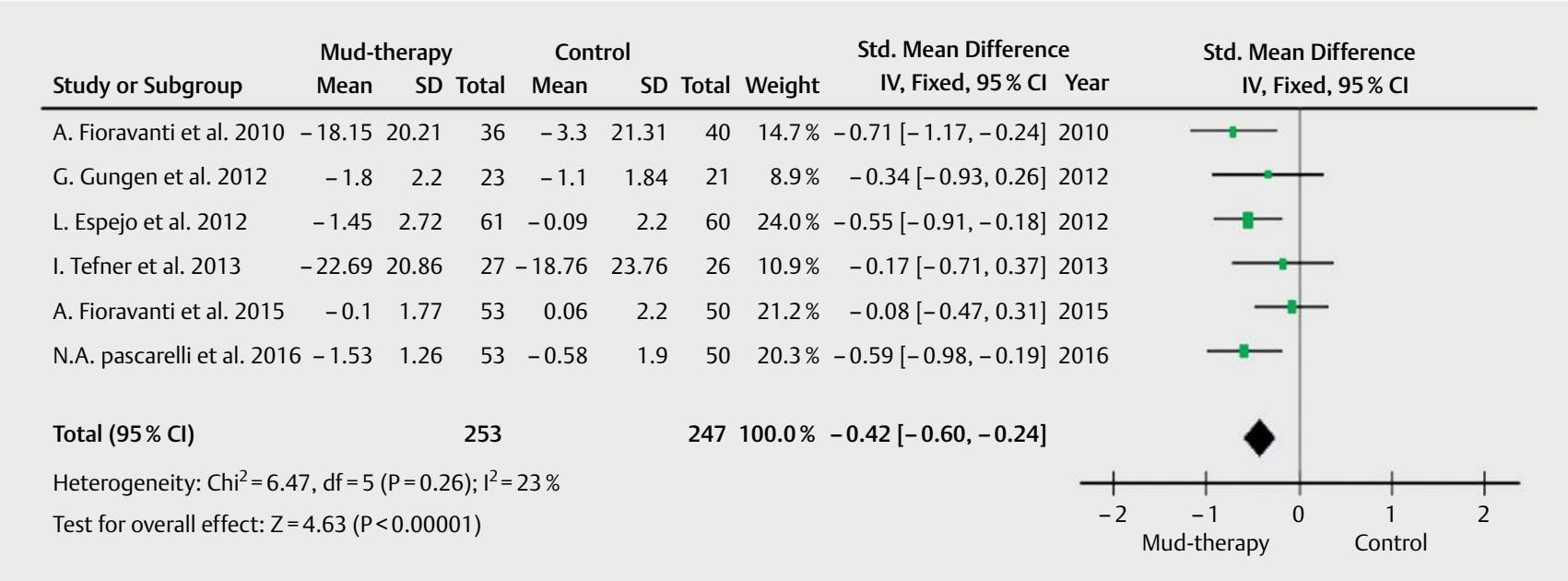

- Fig. 6 Forest plot of the mean differences in WOMAC stiffness scores with 95\% confidence interval between mud therapy group and control group to examine the effect of mud therapy on stiffness relief in patients with knee OA.

score as an outcome ( $\triangleright$ Fig. 4$)$. The result of this meta-analysis indicate that balneotherapy improve the rate of functional improvement by $-64 \%$ when compared with the controls, there was significant difference between 2 groups (SMD $=-0.64 ; 95 \% \mathrm{Cl}-1.09$ to $-0.19 ; p=0.005)$. There was higher degree of late statistical heterogeneity was observed across the studies $\left(I^{2}=74 \% ; p=0.002\right)$, which supported the application of random effects model [15].

\section{Meta-analysis of the effects of mud therapy on WOMAC in patients with knee OA}

Among ten studies included in this meta-analysis, there were 6 clinical studies [10, 16, 21-24], including 253 treatment cases and 247 control cases that measured effectiveness of mud therapy in patients with knee OA and measured WOMAC pain score as an outcome ( $\vdash$ Fig. 5 ).
The result of this meta-analysis indicate that mud therapy reduced the pain score by $-42 \%$ when compared with the controls, there was a significant difference between 2 groups ( $S M D=-0.42$; $95 \% \mathrm{Cl}-0.83$ to $-0.02 ; \mathrm{p}<0.04)$. There was higher degree of late statistical heterogeneity was observed across the studies $\left(\mathrm{I}^{2}=80 \%\right.$; $p=0.0002)$, which supported the application of random effects model [15].

These same 6 studies $[10,16,21-24]$ also measured the WOMAC stiffness score as an outcome ( $\vee$ Fig. $\mathbf{6}$ ). The result of this meta-analysis indicate that mud therapy improve the rate of relieving stiffness by $-42 \%$ when compared with the controls, there was significant difference between 2 groups $(S M D=-0.42 ; 95 \% \mathrm{Cl}$ -0.60 to $-0.24 ; p=0.00001)$. There was low degree of statistical heterogeneity was observed $\left(I^{2}=23 \% ; p=0.26\right)$. 


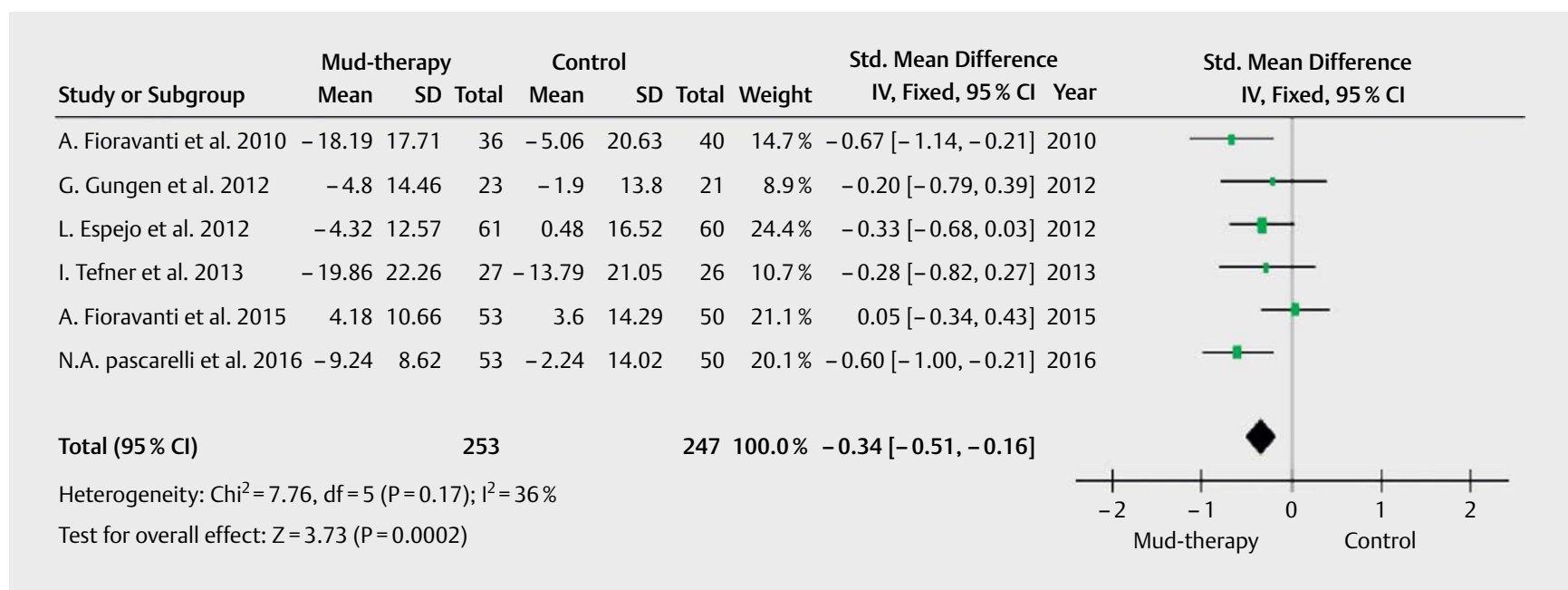

Fig. 7 Forest plot of the mean differences in WOMAC function score with 95\% confidence interval between mud therapy group and control group to examine the effect of mud therapy on improvement of physical function in patients with knee OA.

These same 6 studies $[10,16,21-24]$ also measured the WOMAC function score as an outcome ( $\vee$ Fig. 7 ). The result of this meta-analysis indicate that mud therapy improve the rate of functional improvement by $-34 \%$ when compared with the controls, there was significant difference between 2 groups ( $S M D=-0.34$; $95 \% \mathrm{Cl}-0.51$ to $-0.16 ; \mathrm{p}=0.0002)$. There was low degree of late statistical heterogeneity was observed across the studies ( $I^{2}=36 \%$; $p=0.17)$.

\section{Discussion}

This meta-analysis included 5 clinical trial studies (16-20) showing the effect of balneotherapy and 6 clinical trial studies [10, 16, 2124 ] showing the effect of mud therapy on pain relief, stiffness and functional improvement for patients with knee OA as measured by WOMAC pain, stiffness and function scores. Many previous studies have found that balneotherapy, with or without mud therapy had a significant effect on pain relief, stiffness and functional improvement. A meta-analysis on mud therapy for patients with knee OA indicated that weather mudpack therapy, used alone or in combination with hydrotherapy, was not a factor significantly associated with high heterogeneity; the meta-analysis also highlighted the necessity of including combination therapy [40].

Ten clinical trial studies were included in this meta-analysis. There is a high heterogeneity among studies which measure the effect of balneotherapy (0-76\%) and among the studies which measure the effect of mud therapy (23-80\%). First of all, there is a clinical heterogeneity that is due to different interventions, methods, different intervention time periods, different control groups as well as a difference in follow-up periods. Another relevant factor is the difference in the components of mud, used for mud therapy as well as components of mineral water used for balneotherapy; one study [20] even did not disclose the ingredients of water. The location of the hot springs and the country in which it resides may also affect heterogeneity. In addition, the treatment of the control group varied study to study and included no intervention, tap water and hot packs.

In case of balneotherapy the follow-up time for evaluating the WOMAC pain, stiffness and function scores outcomes were range from 1 to 12 months, although the period of intervention was about 2 to 6 weeks. For mud therapy, the follow-up time for evaluating the WOMAC scores outcomes were range from 11 days to 12 months, although the period of intervention was about 11 days to 2 weeks.

The last follow-up time after the intervention is important in determining the continuing effect of mud therapy and balneotherapy. Only one study [22] in this meta-analysis did not show significant improvement in WOMAC pain and WOMAC function scores after treatment with mudpack therapy; because the last follow-up time was 12 months and this relatively long time span was one possible reason. In this meta-analysis it is believe that these factors may be related to the resulting differences and impact the overall effects and heterogeneity.

Results of this meta-analysis favoured balneological interventions compared to standard treatment alone when evaluating effects on pain relief, stiffness and functional improvement in patients with knee OA. Findings showed that real balneological interventions such as hot mineral baths or mud/peloid packs were significantly better than tap water immersion or hot packs in improving pain, stiffness and function. This difference is due to specific hydro-mineral and crenotherapeutic mechanisms of action of thermal mineral waters and chemo-physical properties of therapeutic muds/peloids, which can modulate endocrinological changes responsible for reduction of pain and inflammation [16].

A major strength of this meta-analysis is that, all the studies included in this meta-analysis used a randomized controlled design (RCT), thus minimizing the selection bias. Moreover, studies were excluded in which balneotherpy and mud therapy combined with the other interventions. However, there are some limitations to this meta-analysis. First, potential limitation of this meta-analysis 
is relatively small number of included studies using the same outcome measure i. e. WOMAC, which makes it difficult to draw a firm conclusion. Second, is substantial heterogeneity among the studies for WOMAC stiffness and function scores in balneotherapy, and WOMAC pain score in mud therapy studies; therefore, to identify the factors causing heterogeneity additional studies would be needed to perform subgroup analyses. Third, each study had a different protocol for mud therapy and balneotherapy treatment and spas were located in different areas and in different countries.

\section{Conclusion}

In conclusion, this meta-analysis confirm that existing clinical trials that evaluated the effectiveness of balneotherapy and mud therapy found that it seems to have a role in the treatment of knee OA and it is significantly associated with a reduction in pain, stiffness and functional improvement in patients with knee OA.

The improvement reported in some clinical trials lasts over time, so balneotherapy and mud therapy can represent a useful backup to pharmacologic treatment of knee OA patients or an alternative for patients who are unable to tolerate pharmacologic treatments. However, in this meta-analysis there are relatively small numbers of studies that have been undertaken to investigate effectiveness of balneotherapy and mud therapy in knee OA, so it is difficult to make definitive conclusions. Additional high quality, randomized controlled trials need to be conducted to explore the issues further in order to obtain strong evidence on the effects of balneotherapy and mud therapy.

\section{Conflict of interest}

The authors declare that they have no conflict of interest.

\section{References}

[1] Zhang Y, Jordan JM. Epidemiology of osteoarthritis. Clin Geriatr Med 2010; 26: 355-369. Available at: https://www.sciencedirect.com/ science/article/pii/S0749069010000261?via \%3Dihub

[2] Murray C], Vos T, Lozano R et al. Disability-adjusted life years (DALYs) for 291 diseases and injuries in 21 regions, 1990-2010: a systematic analysis for the Global Burden of Disease Study 2010. Lancet 2012; 380: 2197-2223. Available at: https://www.sciencedirect.com/ science/article/pii/S0140673612616894?via \%3Dihub

[3] Cross M, Smith E, Hoy D et al. The global burden of hip and knee osteoarthritis: estimates from the Global Burden of Disease 2010 study. Ann Rheum Dis 2014; 73: 1323-1330. Available at: https://ard. bmj.com/content/73/7/1323

[4] Hunter D], Schofield D et al. The individual and socioeconomic impact of osteoarthritis. Nat Rev Rheumatol 2014; 10: 437-441. Available at: https://www.nature.com/articles/nrrheum.2014.44

[5] Jordan KM, Arden NK et al. EULAR Recommendations 2003: an evidence based approach to the management of knee osteoarthritis: report of Task Force of the Standing Committee for International Clinical Studies Including Therapeutic Trials (ESCISIT). Ann Rheum Dis 2003; 62: 1145-1155. Available at: https://www.ncbi.nlm.nih.gov/ pmc/articles/PMC1754382/
[6] Bender T, Karagülle Z, Bálint GP et al. Hydrotherapy, balneotherapy, and spa treatment in pain management. Rheumatol Int 2005; 25: 220-224. Available at: https://link.springer.com/article/10.1007\%2Fs00296-0040487-4

[7] Özkuk K, Gürdal H, Karagülle M et al. Balneological outpatient treatment for patients with knee osteoarthritis; an effective non-drug therapy option in daily routine. Int J Biometeorol 2017; 61: 719-728. Available at: https://link.springer.com/article/10.1007/s00484-016$1250-8$

[8] Hochberg MC, Altman RD, April KT et al. American College of Rheumatology 2012 recommendations for the use of nonpharmacologic and pharmacologic therapies in osteoarthritis of the hand hip, and knee. Arthritis Care Res (Hoboken) 2012; 64: 465-474. Available at: https://www.ncbi.nlm.nih.gov/pubmed/22563589

[9] Vaishya R, Vijay V et al. Non-operative management of osteoarthritis of the knee joint. J Clin Orthop Trauma 2016; 7: 170-176. Available at: https://www.ncbi.nlm.nih.gov/pmc/articles/PMC4949406/

[10] Tefner IK, Gaál R, Koroknai A et al. The effect of Neydharting mud-pack therapy on knee osteoarthritis: a randomized, controlled, double-blind follow-up pilot study. Rheumatol Int 2013; 33: 2569-2576. Available at: https://link.springer.com/article/10.1007/s00296-013-2776-2\#citeas

[11] Liberati A, Altman DG, Tetzlaff ] et al. The PRISMA statement for reporting systematic reviews and meta-analyses of studies that evaluate health care interventions: explanation and elaboration. Ann Intern Med 2009; 151: 65-94. Available at: https://journals.plos.org/ plosmedicine/article?id = 10.1371/journal.pmed. 1000100

[12] Gentelle-Bonnassies S, Le Claire P, Mezieres M et al. Comparison of the responsiveness of symptomatic outcome measures in knee osteoarthritis. Arthritis Care Res 2000; 13: 280-285. Available at: https://onlinelibrary.wiley. com/doi/pdf/10.1002/1529-0131\%28200010\%2913\%3A5\%3C280\%3A\%3AAID-ANR6\%3E3.0.CO\%3B2-6

[13] Higgins JPT, Green S. Assessment of study quality. Cochrane handbook for systematic reviews of interventions 4.2.5 [update May 2005]; section 6. The Cochrane Library. 2005; 6: Available at: http://aaz.hr/ resources/pages/57/6. \%20Cochrane $\% 20$ Handbook $\% 20$ for $\% 20$ Syst\%20Review \%202006.pdf

[14] Egger M, Smith GD, Schneider M et al. Bias in meta-analysis detected by a simple, graphical test. BMJ 1997; 315: 629-634. Available at: https://www.bmj.com/content/315/7109/629.long

[15] DerSimonian R, Laird N. Meta-analysis in clinical trials. Control Clin Trials 1986; 7: 177-188. Available at: https://www.sciencedirect.com/ science/article/pii/0197245686900462?via\%3Dihub

[16] Fioravanti A, lacoponi F, Bellisai B et al. Short- and long-term effects of spa therapy in knee osteoarthritis. Am J Phys Med Rehabil 2010; 89: 125-132. Available at: https://www.sciencedirect.com/science/article/ pii/S1877065716000361

[17] Tishler M, Rosenberg O, Levy O et al. The effect of balneotherapy on osteoarthritis. Is an intermittent regimen effective? Eur J Intern Med 2004; 15: 93-96. Available at: https://www.ejinme.com/article/ S0953-6205(04)00005-6/fulltext

[18] Fazaa A, Souabni L, Ben Abdelghani K et al. Comparison of the clinical effectiveness of thermal cure and rehabilitation in knee osteoarthritis. A randomized therapeutic trial. Ann Phys Rehabil Med 2014; 57 : 561-569. Available at: https://www.sciencedirect.com/science/article/ pii/S187706571401793X?via\%3Dihub

[19] Hanzel A, Horvat K, Berenyi K et al. Clinical improvement of patients with osteoarthritis using thermal mineral water at Szigetvár Spa - results of a randomised double-blind controlled study. Int J Biometeorol 2018; 62: 253-259. Available at: https://link.springer.com/article/10.1007\%2Fs00484-017-1446-6 
[20] Uysal B, Ozkuk K. Effectiveness of balneotherapy in knee osteoarthritis. Exp Biomed Res 2018; 1: 46-54. Available at: https://www. experimentalbiomedicalresearch.com/ojs/index.php/ebr/article/ view $/ 11 / 8$

[21] Güngen G, Ardic F, Fındıkoğlu G et al. The effect of mud pack therapy on serum YKL-40 and hsCRP levels in patients with knee osteoarthritis. Rheumatol Int 2012; 32: 1235-1244. Available at: https://link. springer.com/article/10.1007\%2Fs00296-010-1727-4

[22] Fioravanti A, Bacaro G, Giannitti C et al. One-year follow-up of mud-bath therapy in patients with bilateral knee osteoarthritis: a randomized, singleblind controlled trial. Int J Biometeorol 2015; 59: 1333-1343. Available at: https://link.springer.com/article/10.1007\%2Fs00484-0140943-0

[23] Espejo L, Caro B, Cardero M et al. Effects of mud pack therapy on patients with knee osteoarthritis. A randomized controlled clinical trial. Anales de Hidrología Médica 2012; 5: 109-121. Available at: https:// revistas.ucm.es/index.php/ANHM/article/viewFile/40192/38598

[24] Pascarelli NA, Cheleschi S, Bacaro G et al. Effect of Mud-Bath Therapy on Serum Biomarkers in Patients with Knee Osteoarthritis: Results from a Randomized Controlled Trial. Isr Med Assoc J 2016; 18: 232-237. Available at: https://www.ima.org.il/FilesUpload/ IMAJ/0/193/96925.pdf

[25] Fioravanti A, Giannitti C, Bellisai B et al. Efficacy of balneotherapy on pain, function and quality of life in patients with osteoarthritis of the knee. Int J Biometeorol 2012; 56: 583-590. Available at: https://link. springer.com/article/10.1007\%2Fs00484-011-0447-0

[26] Fraioli A, Serio A, Mennuni $G$ et al. A study on the efficacy of treatment with mud packs and baths with Sillene mineral water (Chianciano Spa Italy) in patients suffering from knee osteoarthritis. Rheumatol Int 2011; 31: 1333-1340. Available at: https://link.springer.com/ article/10.1007\%2Fs00296-010-1475-5

[27] Ceccarelli F, Perricone C, Alessandri C et al. Exploratory data analysis on the effects of non pharmacological treatment for knee osteoarthritis. Clin Exp Rheumatol 2010; 28: 250-253. Available at: https://www. clinexprheumatol.org/abstract.asp?a $=744$

[28] Gaal J, Varga J, Szekanecz Z et al. Balneotherapy in elderly patients: effect on pain from degenerative knee and spine conditions and on quality of life. Isr Med Assoc J 2008; 10: 365-369. Available at: https://www.ima. org.il/MedicinelMAJ/viewarticle.aspx?year $=2008 \&$ month $=05 \&$ page $=365$

[29] Karagulle M, Kardes S, Disci R et al. Spa therapy for elderly: a retrospective study of 239 older patients with osteoarthritis. Int J Biometeorol 2016; 60: 1481-1491. Available at: https://link.springer. com/article/10.1007\%2Fs00484-016-1138-7

[30] Forestier R, Desfour H, Tessier JM et al. Spa therapy in the treatment of knee osteoarthritis: a large randomised multicentre trial. Ann Rheum Dis 2010; 69: 660-665. Available at: https://www.ncbi.nlm.nih.gov/ pmc/articles/PMC2927613/
[31] Kulisch A, Benko A, Bergmann A et al. Evaluation of the effect of Lake Heviz thermal mineral water in patients with osteoarthritis of the knee: a randomized, controlled, single-blind, follow-up study. Eur J Phys Rehabil Med 2014; 50: 373-381. Available at: https://www. minervamedica.it/en/journals/europa-medicophysica/article. php?cod = R33Y2014N04A0373

[32] Wigler I, Elkayam O, Paran D et al. Spa therapy for gonarthrosis: A prospective study. Rheumatol Int 1995; 15: 65-68. Available at: https://link.springer.com/article/10.1007\%2FBF00262710\#citeas

[33] Forestier R, Genty C, Waller B et al. Crenobalneotherapy (spa therapy) in patients with knee and generalized osteoarthritis: a post-hoc subgroup analysis of a large multicentre randomized trial. Ann Phys Rehabil Med 2014; 57: 213-227. Available at: https://www.sciencedirect.com/science/article/pii/S187706571400044X?via \%3Dihub

[34] Fioravanti A, Cantarini L, Bacarelli MR et al. Effects of spa therapy on serum leptin and adiponectin levels in patients with knee osteoarthritis. Rheumatol Int 2011; 31: 879-882. Available at: https://link. springer.com/article/10.1007\%2Fs00296-010-1401-x

[35] Kilicoglu O, Donmez A et al. Effect of balneotherapy on temporospatial gait characteristics of patients with osteoarthritis of the knee. Rheumatol Int 2010; 30: 739-747. Available at: https://link.springer. com/article/10.1007\%2Fs00296-009-1054-9

[36] Ceccarelli F, Perricone C, Alessandri C et al. Exploratory data analysis on the effects of non pharmacological treatment for knee osteoarthritis. Clin Exp Rheumatol 2010; 28: 250-253. Available at: https://www. clinexprheumatol.org/abstract.asp?a $=744$

[37] Karagulle M, Karagulle MZ, Karagulle O et al. A 10-day course of SPA therapy is beneficial for people with severe knee osteoarthritis. A 24-week randomised, controlled pilot study. Clin Rheumatol 2007; 26: 2063-2071. Available at: https://link.springer.com/article/10.1007\%2Fs10067-0070618-x

[38] Cantarini L, Leo G, Giannitti C et al. Therapeutic effect of spa therapy and short wave therapy in knee osteoarthritis: a randomized, single blind, controlled trial. Rheumatol Int 2007; 27: 523-529. Available at: https://link.springer.com/article/10.1007\%2Fs00296-006-0266-5

[39] Yilmaz B, Goktepe AS, Alaca R et al. Comparison of a generic and a disease specific quality of life scale to assess a comprehensive spa therapy program for knee osteoarthritis. Joint Bone Spine 2004; 71: 563-566. Available at: https://www.sciencedirect.com/science/article/ pii/S1297319X03002021?via\%3Dihub

[40] Xiang J, Wu D et al. Clinical Efficacy of Mudpack Therapy in Treating Knee Osteoarthritis: A Meta-Analysis of Randomized Controlled Studies. Am J Phys Med Rehabil 2016; 95: 121-131. Available at: https://www.ncbi.nlm.nih.gov/pmc/articles/PMC4704659/ 